\title{
Reflections on College Chinese Teaching Reform
}

\author{
Zhou Jie \\ Foreign Languages and Cultures Department \\ Beijing Wu Zi University \\ Beijing, China \\ zhoujie@bwu.edu.cn
}

\begin{abstract}
This paper, based on the orientation of College Chinese Teaching Curriculum, has made a comprehensive analysis on the current College Chinese teaching reform. Research shows that successful teaching reform must be carried out simultaneously in a number of aspects concerned, such as teacher and student education, compiling new teaching materials as well as adopting effective teaching approaches, etc. Moreover, the author of this paper has also made detailed explanations on implementing plans of teaching innovations in the hope of improving college students' humane quality in College Chinese class.
\end{abstract}

Keywords-College Chinese; teaching reform; Teaching Curriculum

\section{INTRODUCTION}

College Chinese, as a compulsory basic course offered in Colleges/universities, has been ineffective in terms of teaching efficiency. Various problems have been pinpointed in current College Chinese teaching, such as insufficient teaching hours, ineffective teaching approaches as well as out-of-date teaching ideas, etc. Moreover, it has yet become a controversial issue for a long time as to whether College Chinese should be offered in current colleges/universities.

However, the Ministry of Education of the People's Republic of China has clearly stated that COLLEGE CHINESE should be offered in normal undergraduate colleges/universities. What's more, the Department of Higher Education has also emphasized that "humanistic education" should be regarded as a new trend in the educational reform of COLLRGR CHINESE CURRICULUM SYLLABUS. Yang Zhijian, vice director of Department of Higher Education, once pointed out that the primary objective of the COLLEGE CHINESE reform education is to develop students' aesthetic interest. Secondly, it also aims to improve students' aesthetic judgment. In this way[1], College Chinese may improve students' appreciation of the splendor of nature, their understanding of the glorious world, as well as fostering their harmonious mentality and healthy personality. The document has paved the way of COLLEGE CHINESE education. Therefore, as College Chinese teachers, we should exert ourselves to achieve the educational objectives set by the Department of Higher Education, developing students' comprehensive ability through COLLEGE CHINESE teaching.

As a College Chinese teacher, the writer of this paper has more than 20 years' teaching experience. In the past teaching process, attention has been paid to students' response and teaching effect to fulfill the teaching objective of improving students' humanities accomplishment. In the past twenty years, the teaching group in the writer's department has used a number of different textbooks and made attempts in practicing teaching reforms of one kind after another from the traditional teacher-centered instruction to student-centered learning. At the same time, teaching assessment has also be made. Our study indicates that process assessment has greatly increased class interaction between teacher and students and among students. It can not only increase students' class participation in developing activities, but also enliven class atmosphere, benefiting their class performance in airing their own views as well as expressing themselves clearly and fluently.

In the process of carrying out College Chinese reform, the writer of the paper has attended many College Chinese conference and acquired great insights from associates in a number of aspects from teaching ideas to teaching approaches reforms. And this paper is part of the product of the writer's as well as the teaching group's study and many years' teaching experience.

\section{APPROACHES ADOPTED IN CARRYING OUT EDUCATIONAL REFORM}

In order to achieve the above objective, efforts should be made in the following aspects: improving teacher quality and teaching efficiencies, developing students' awareness of the importance of College Chinese as well as revising the current teaching materials. Only in this way can we ensure the successful reform of the COLLEGE CHINESE education.

\section{A. Upgrading Teacher Quality}

COLLEGE CHINESE is a compulsory course for freshmen who study in normal undergraduate colleges/universities. Hence, the development of teacher quality is of great significance. In the colleges/Universities with Chinese Department, most of the teachers are unwilling to take on the College Chinese course, while in colleges/universities which do not have the Chinese department, it is hard for the teachers to put all their energy into the basic courses, as most of the them devote their time to academic research or things beneficial to them. [2]All these 
factors contribute to the inefficiency of College Chinese teaching. Therefore, It is advisable for all the teachers to exert themselves in improving their own literacy, activating their enthusiasm to fulfill the objectives set the Ministry of Education.

Moreover, College Chinese class hours are insufficient. Currently, the majority of colleges set this course only for one semester, two periods for one week, only a handful of schools have sixty-four teaching hours. So many teachers are confined to simple explanations of texts, as well as reducing teaching content. Actually, it's hard for teacher to make the choices. If taught in the context of literary history, teachers will have less time for text interpretations. However, if taught in terms of humanities, humanistic ideas could be explained clearly, less attention would be paid to the interpretation and appreciation of literary works, deviating from the objectives of Chinese courses teaching objectives. It is an arduous task for all the Chinese teachers as the text interpretations involve a wide range of knowledge. What's more, as the teaching materials have revised with each teaching reform, hence, teachers will devote more time and energy to course preparation, substantially increasing their teaching workload. Nevertheless, in order to explore the new teaching ideas, every teacher should give up individual difficulties, respecting for the greater cooperation with their colleagues, smoothly carrying out the educational reforms.

To further develop College Chinese teaching, College Chinese teachers should be prepared in the following two aspect. Firstly, they should improve themselves by accumulating more knowledge. As a knowledge-based course, the instruction of College Chinese involves knowledge of various fields. However, current College Chinese teachers, though most of whom have doctorate degrees, are only specialized in their own fields, such as literature or linguistics. Hence, they should constantly enrich themselves by learning autonomously to improve their teaching. Secondly, they should also actively participate in their current teaching reforms. With the popularity of Internet in the past decade, MOOC (massive open online course) and Micro-class have been widely applied in courses of every subject. And College Chinese, focusing on improve students' humanities accomplishment, is also under reform. Hence, how to offer College Chinese MOOC and Micro-classes to meet the needs of College students is an arduous task faced by College Chinese teachers.

\section{B. Setting A Requirement for Students}

To fulfill the above teaching objectives, it is of great significance for students to cooperate with their teachers. [3]Hence, at the beginning of each semester, teachers should cultivate students' interest in their College Chinese study, activating their enthusiasm in improving students' humanities through the setting of COLLEGE CHINESE. As Ye Shengtao remarked, "teachers' first responsibility is to impart knowledge, but the more important thing is to guide their students. 'To guide' means instructing teaching methods, i.e. making students acquire knowledge themselves. Ultimately, they will study the science before their teacher explanation."
"The main function of teacher is to guide, let their students work hard and study by themselves."

Due to the negative impact of the examination-oriented education, many students have lost their interests in literature, so helping students to re-cultivate their interests of literature and culture of Chinese is the prerequisite for them to learn COLLEGE CHINESE well. Students are not only asked to learn some literary works by heart, but also to appreciate and savor the essence of literary texts-a deeper understanding and perception of life, society and nature by reading the literary works. Teachers' job, hence, is not only to help the students complete their learning task, but benefit their whole life. Therefore, after students graduate from college/university, they can solve their own problems encountered through selfreading in their life, the ultimate objective of their teachers. [4]

In addition to cultivating students' interests in COLLEGE CHINESE learning, it is also necessary for teachers to stimulate their enthusiasm in Chinese learning, devoting their in-class and out-of-class time to Chinese learning by participating classroom activities and completing assignment set by their teachers. Only in this way can teachers give more opportunities to students in expressing their own views, replacing teachers' authorities of instructing knowledge. When students' interests in Chinese learning are activated, they may actively participate in class discussion and expand their extensive reading after class. Thus, teacher and students cooperation will certainly contribute to the development of their talents and the improvement of their own qualities.

Therefore, to make full use of online resources in the age of big data is required in current College Chinese teaching. Nowadays, most students are smartphone addicts. To arouse their enthusiasm, College Chinese teachers may ask students to surf on the Internet for answers to their questions before summarize or air their own views in College Chinese class. In this way, class interactions are created on the one hand, and more communication has been made between teacher and students. Furthermore, class WeChat group can also be set up to effectively improve College Chinese teaching, as some of the in-class activities can be extended to after-class communication among students.

\section{Improving Teaching Approaches}

Following the adjustments made by the teachers and students, the reform of teaching approaches is imperative. It seems that the traditional teaching methods have to be replaced to fulfill the teaching objectives. [5]

To enliven classroom atmosphere, student participation is preferred. Though college Chinese test, which is no longer so decisive to students' fate as college entrance test, is still important to them, as it does have some effects on their performance assessment, such as scholarship qualifications, choices of major, etc. As a result, when teachers work out their schemes in participatory teaching, it is necessary to predesign the specific contents for students to be involved in, choosing the specific approach on how to evaluate students' performance. We must guarantee the fairness, avoiding teacher-students contradictions caused by assessment standards. 
In addition, to meet the requirements of participatory teaching approach, traditional exam pattern should also be improved. Hence, process assessment should be preferred. Traditional College Chinese assessment is mainly determined by students' performance in their end-term exam, while process assessment mainly focuses on their usual class performance and term paper grade. In this way, students are required to accomplish their independent learning tasks consciously and seriously, actively participating in-class activities, including preparations before class and timely afterclass review.

Hence, process assessment, considering its pros and cons, should be implemented in current College Chinese teaching evaluation. This is due to the fact that on the one hand, students' overall evaluation consists of various aspects, and it's hard define students' comprehensive ability in terms of exam scores; moreover, process assessment can cultivate students' learning autonomy and improving their personal accomplishment by participating both in-class and extracurricular activities required by the College Chinese on the other. Thus, students' humanities accomplishment can be developed, fulfilling the objectives of College Chinese teaching.

\section{Updating Teaching Materials}

With the gradual development of the COLLEGE CHINESE Curriculum Reform, the style of teaching has also been reformed.[6] Initially, the vast majority of textbooks based on the history of Chinese literature were written, from the Qin and Han Dynasties to modern and contemporary literature, but less devoted to the foreign literature. Later, with the transformation of the teaching ideas, a series of modules of teaching materials in terms of ideological feelings emerged. The contents were divided into more than a dozen modules on the basis of people's feelings and thoughts. And each module is complemented by a number of corresponding literary works. These two types of teaching materials both have its pros and cons. The former one, which is much like a compendium of Chinese literary history, is too specialized to non-Chinese major students, as it is difficult to arouse students' interest. The latter one, which has been used in our school for several years, requires more explanations of the teachers, leading to insufficient appreciation of literary works.

Hence, appropriate COLLEGE CHINESE textbooks, reflecting both literary traits as well as helping students broaden their cultural horizons, are in urgent need. Professor Yang Lin, a staff member of GuangDong University of Finance, once proposed a creative and practical style of teaching materials, which could extend the cultural themes or topics from literary works. For example, he suggested that we could interpret the Chinese poetry culture through ancient poetry. more traditional strategies of Chinese Culture, through learning Legend of Spring and Autumn Century by Zuo Qiuming, could be introduced and put into practice in our real life. If successfully compiled, the teaching materials will surely help teachers focus on their teaching contents. Meanwhile, teaching efficiency could also be raised as a result of the difference of College Chinese teachers' differing professional backgrounds, bypassing their respective weaknesses.

Besides, interesting scripts are effective teaching materials in compiling textbooks and they are guarantees of a high-quality class. As a result, College Chinese teachers, as both the instructor of knowledge and organizer of class activities, should pay more attention to students' interests, laying a solid foundation on compiling textbooks in selecting high-quality teaching materials. Moreover, attempts can also be made by students in practicing compiling textbooks of different styles to further improve College Chinese teaching.

\section{CONCLUSION}

In the 18th Party Congress, construction of excellent traditional culture inheritance and carrying forward Chinese excellent traditional culture have been proposed as our current significant task. To cultivate the new era talents, the above goal could be achieved only by internalizing our Chinese excellent cultural tradition and combining with human practice. At the same time, it has also been emphasized to improve people's ideological and moral qualities as well as scientific and cultural qualities in the congress. College Chinese teaching is, thus, a guarantee to improve college students' moral quality.

To conclude, College Chinese, as a compulsory course, is beneficial to college students in improving their overall quality. However, it also requires all the College Chinese teachers to take the course seriously, devoting more time and effort to the current College Chinese reform. Our efforts will be paid off in improving students' appreciation of literary works as well as their quality of Chinese culture.

\section{REFERENCES}

[1] Li, B. On Teaching, People Education Publishing Press, 1991.

[2] Wen,R., “A tentative practice of College Chinese teaching reform," Chinese Reading Newspaper,2003 (6)

[3] Li, X., "Reflections on College Chinese teaching," Journal of Chinese university teaching, 2005 (2).

[4] Yang, L. \& Li, C., "Extensive pattern of Chinese-human-culture in College Chinese teaching," Journal of Heilongjiang Higher Education, 2009 (2).

[5] Deng, W., "On College Chinese education and strategies of cultivating college students humanistic quality," Journal of Higher Education Research,2009(3).

[6] Wang, B., "On creative and diversified thinking in teaching materials innovations of College Chinese," Journal of Jiangsu Higher Education, 2001 (3) 